
sponsored by the United States Government. Neither the United States nor the United States Energy Research and Development Administration, nor any of their employees, nor any of their contractors, subcontractors, or their employees, makes any warranty, express or implied, or assumes any legal liability or responsibility for the accuracy, completeness or usefulness of any information, apparatus, product or process disclosed, or represents that its use would not infringe privately owned rights.

\title{
ANALYSIS AND DESIGN SIGNIFICANCE OF IMPEDANCE RING LOSS COEFFICIENT COMPONENT TEST RESULTS
}

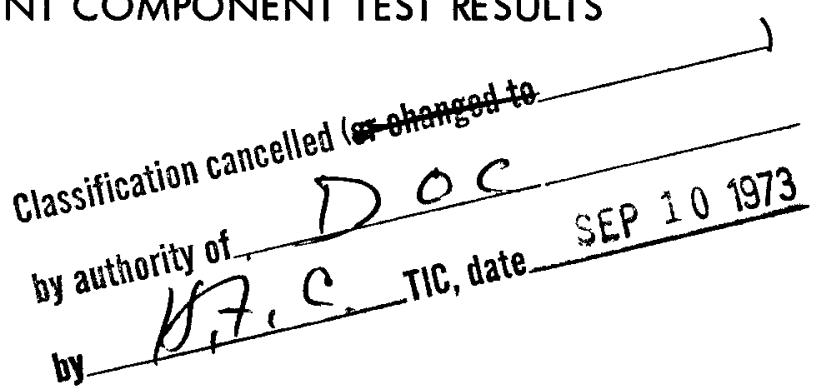

Prepared By:

C.I. hivele

A. I. Miller
Approved By:

K. Rick as

K. Rieke

5.G. gallaghu

J. G. Gallagher F D.R

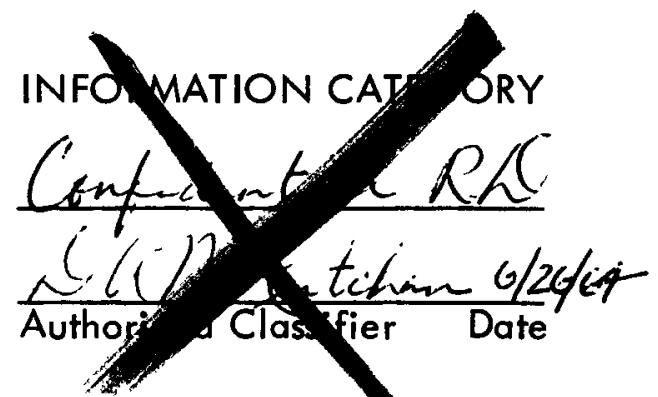

DETERINAI

class:

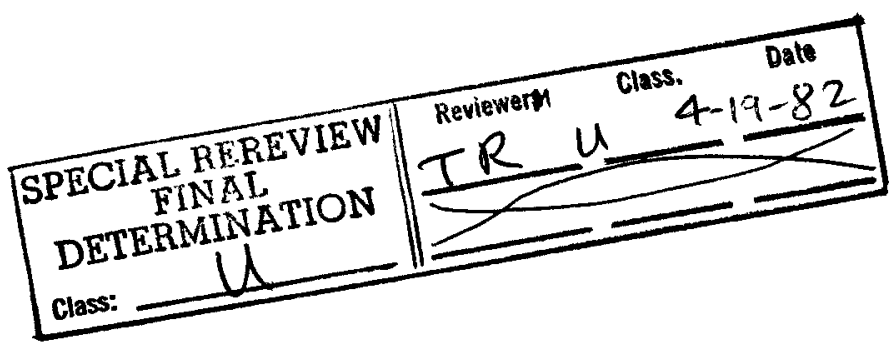

Westinghouse Electric Corporation

Astronuclear Laboratory

Large, Pennsylvania

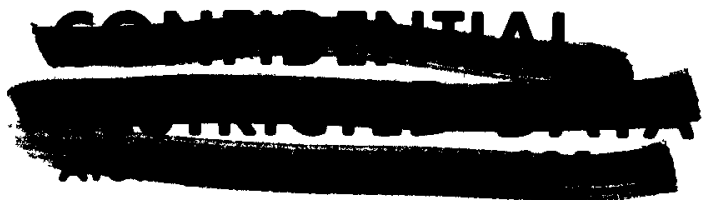




\section{DISCLAIMER}

This report was prepared as an account of work sponsored by an agency of the United States Government. Neither the United States Government nor any agency Thereof, nor any of their employees, makes any warranty, express or implied, or assumes any legal liability or responsibility for the accuracy, completeness, or usefulness of any information, apparatus, product, or process disclosed, or represents that its use would not infringe privately owned rights. Reference herein to any specific commercial product, process, or service by trade name, trademark, manufacturer, or otherwise does not necessarily constitute or imply its endorsement, recommendation, or favoring by the United States Government or any agency thereof. The views and opinions of authors expressed herein do not necessarily state or reflect those of the United States Government or any agency thereof. 


\section{DISCLAIMER}

Portions of this document may be illegible in electronic image products. Images are produced from the best available original document. 


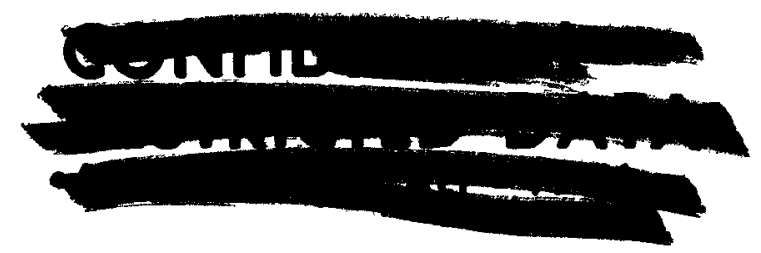

\section{CONCLUSIONS AND RECOMMENDATIONS}

Experimental test results of the loss coefficients for the impedance rings in the inner reflector-outer reflector and outer reflector-pressure vessel annuli and the analytically predicted values compare favorably.

It is recommended that the loss coefficients (based upon the impedance area) used in future reflector system thermal and fluid flow analyses be as follows:

Annulus of

Inner Reflector-Outer Reflector (0.130 inches)

Outer Reflector-Pressure Vessel
Loss Coefficient (based upon impedance area)

0.32

1.22

\section{BACKGROUND}

Flow in the annuli between the inner and outer reflector and between the outer reflector and pressure vessel wall is controlled by impedance rings.

The determination of the flow characteristics of these two impedance rings is of fundamental importance in setting the flow distribution in the reflector system. Thus, a series of flow tests were performed by the WANL Fluid Flow Laboratory on these two impedance rings. The results of these tests and detailed descriptions of the test fixtures have been reported.' $2,3,4$

1. WANL-TME-523 - Test Series C 1, Experimental Determination of the Pressure Loss Coefficient for the Impedance Ring in the Inner Reflector-Outer Reflector Annulus, V. R. Amatange lo, 9/20/63.

2. WANL-TME-669 - Test Series C 1, An Experimental Determination of the Pressure Loss Coefficients for the Inner Reflector-Outer Reflector Annulus, V. R. Amatangelo, 1/29/64. 3. WANL-TME-825 - An Experimental Determination of the Loss Coefficients for the Inner Impedance Ring Using Air and Hydrogen, O. P. Gormley. 4. WANL-TME-825 - An Experimental Determination of the Outer Impedance Ring Loss Coefficient, W. L. Jacob.

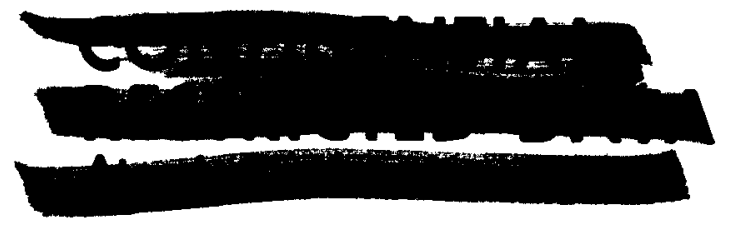


This report presents the design significance of the test results and their application to actual reactor operation. In so doing, it complies with the NRX-A2 component test analysis requirements. 5

\section{TEST RESULTS}

Inner Reflector-Outer Reflector Annulus Impedance Ring

The impedance ring in the annulus between the inner and outer reflector is located near the flow channel exit. It is attached to the aluminum barrel and consists of the circumferentially stepped band shown in figure 1 .

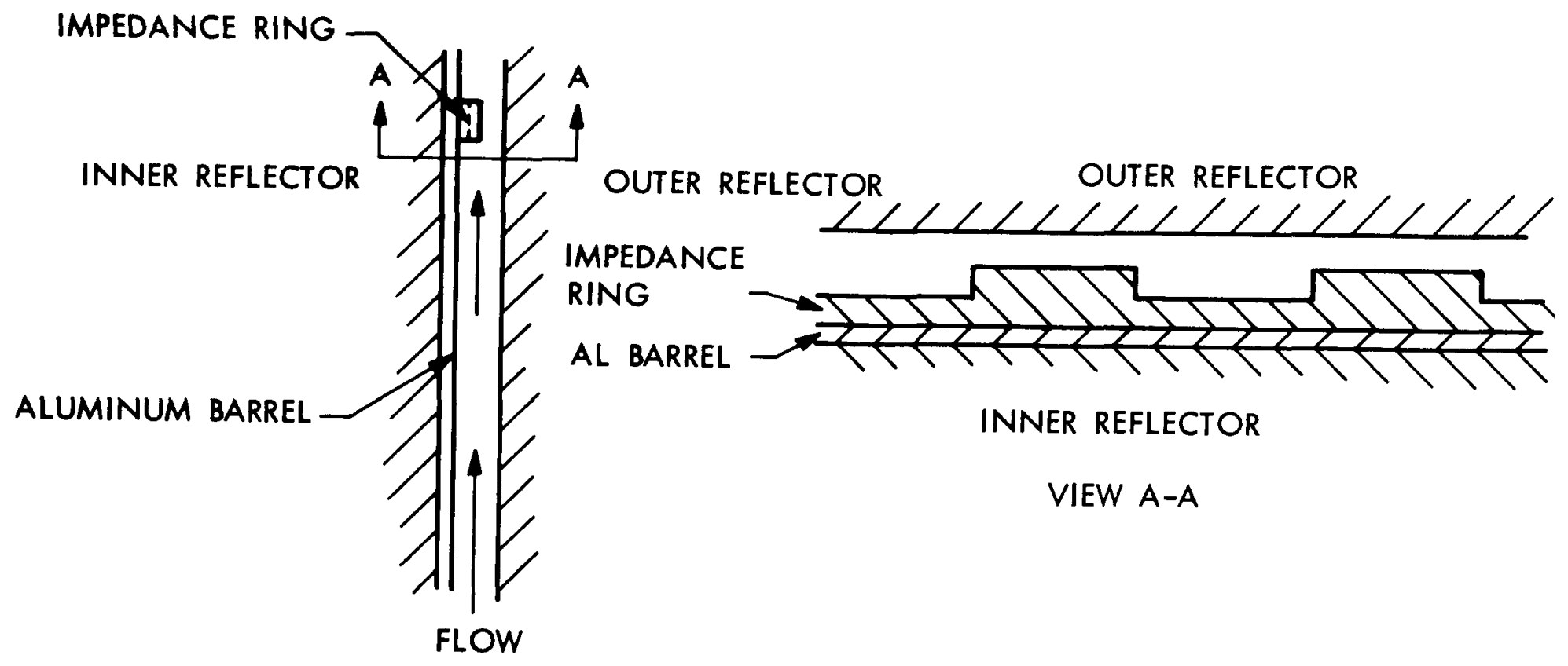

FIGURE 2 INNER REFLECTOR-OUTER REFLECTOR-IMPEDANCE RING

5. AGC Letter, 775:NSD:445 - Prerequisite to NRX-A2 Power Testing, S. L. Abramson, $3 / 20 / 64$

6. WANL-TME-728 - Component Testing Pre-Requisite to NRX-A2 Power Testing, S. L. Abramsoi., 3/20/64. 


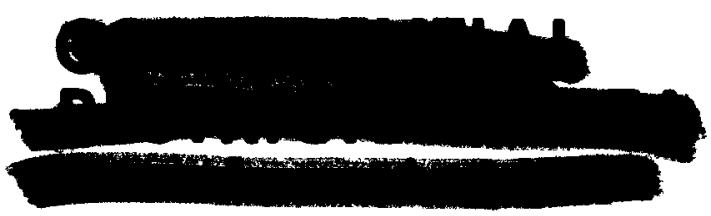

The annular gap between the aluminum barrel and the outer reflector varies from the ambient assembled condition to the full power operating condition. The impedance ring flow area varies in a corresponding fashion. However, the annular gap is prevented from going below 0.065 inches under all operating conditions by the use of axial spacer bars attached to the aluminum barrel.

At assembly the annulus has a dimension of 0.085-0.014 inches, and at full power, steady state operating conditions its calculated 8 width is:

$$
\begin{aligned}
& 0.107 \pm 0.010 \text { at the dome end (at impedance ring) } \\
& 0.094 \pm 0.010 \text { at the mid-core, and } \\
& 0.123 \pm 0.010 \text { at the nozzle end. }
\end{aligned}
$$

Thus, the annulus width at the impedance ring can vary from a minimum of 0.076 inches at assembly, to a maximum of 0.117 inches, at 100 percent full power, if the reflectors are concentric.

The series of flow tests 1, 2, 3 performed in the WANL Fluid Flow Laboratory utilized a model consisting of a $10^{\circ}$ sector of the annulus and impedance ring. During the tests, the annulus width was varied between nominal dimensions of 0.065 inches to 0.130 inches. Both air and hydrogen were used as the working fluid with air used for all annuli and hydrogen for only the 0.080 inch and 0.130 inch annuli. Since the model was limited to only a $10^{\circ}$ sector due to the available gas flow capacity of the laboratory, two overlapping $10^{\circ}$ sector configurations, shown in figure 2, were tested separately.

1. WANL-TME-523-Test Series Cl, Experimental Determination of the Pressure Loss Coefficient for the Impedance Ring in the Inner Reflector-Outer Reflector Annulus, V. R. Amatangelo, 9/20/63.

2. WANL-TME-669-Test Series Cl, An Experimental Determination of the Pressure Loss Coefficients for the Inner Reflector-Outer Reflector Annulus, V. R. Amatangelo, 1/29/64.

3. WANL-TME-826-An Experimental Determination of the Loss Coefficients for the Inner Impedance Ring Using Air and Hydrogen. O. P. Gormley.

8. A WANL Internal Communication from W. G. Brussalis, Reactor Mechanical Design, Serial $40: 21-3 L$. 

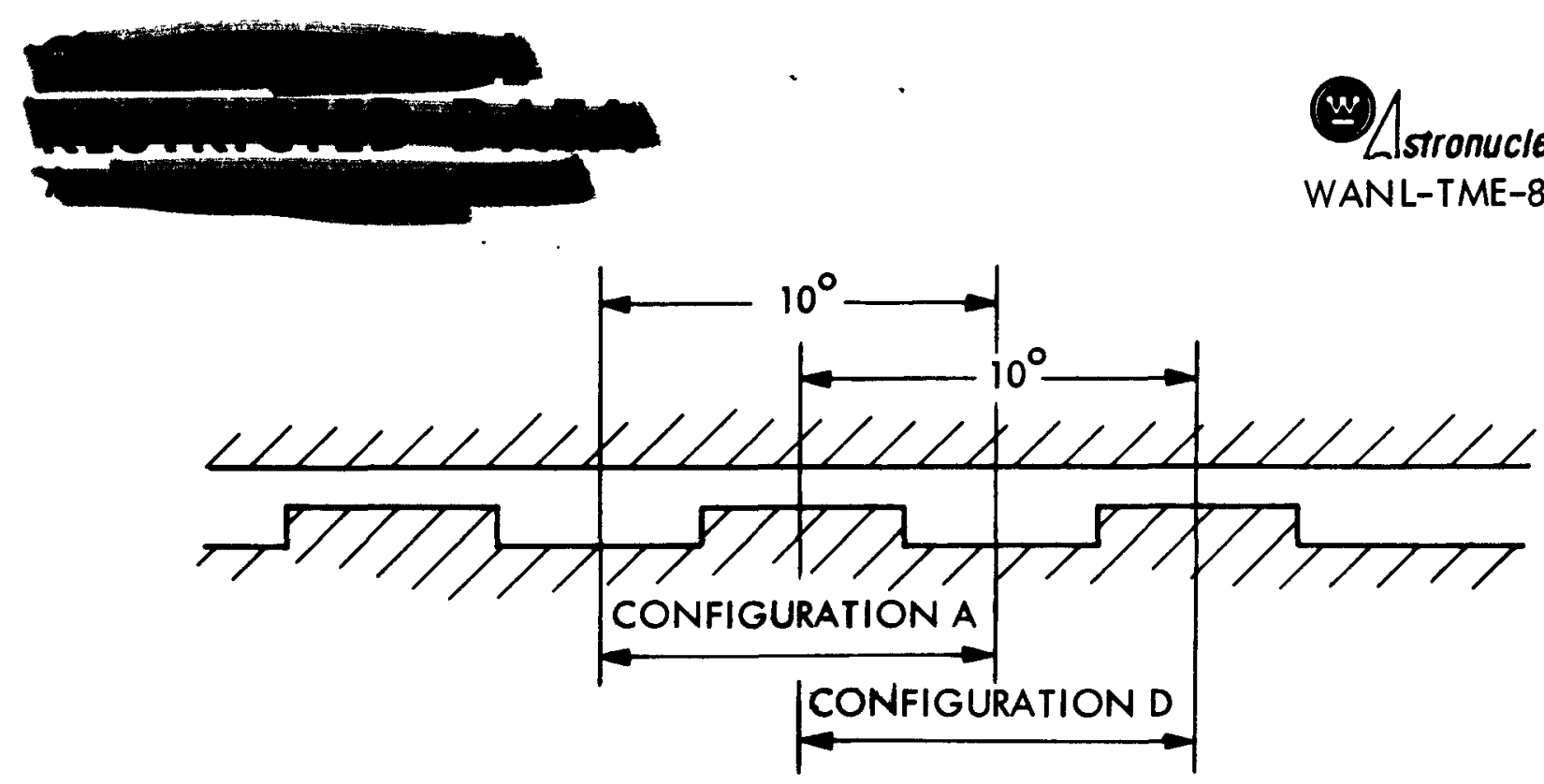

- FIGURE $210^{\circ}$ SECTOR TEST CONFIGURATION

Test results $1,2,3$ show that the impedance ring loss coefficient is independent of Reynolds Number in the absence of compressibility effects in the range investigated. These results are summarized in figure 3 , where the impedance ring loss coefficient (based upon the impedance ring area) is plotted against the impedance ring area. It can be seen that reasonable agreement is obtained between the air and hydrogen test data for each configuration. However, the loss coefficient obtained for configuration $D$ was in all cases higher than that obtained for configuration $A$ for the same flow area. This apparent discrepancy is attributed to the fact that configuration $A$ acts like a single restriction while configuration $D$ acts like a dual restriction. For the same flow area the latter have higher losses than the former, due to the presence of two flow boundaries instead of one. Another possible cause for the discrepancy is the greater side wall effects inherent in configuration $D$ than in configuration $A$. In the former, the side wall sees a higher bulk velocity than in the latter. In the full scale reactor, the impedance ring should act like a restriction somewhere between these two limits.

1. WANL-TME-523 - Test Series C1, Experimental Determination of the Pressure Loss Coefficient for the Impedance Ring in the Inner Reflector-Outer Reflector Annulus, V. R. Amatangelo, 9/20/63.

2. WANL-TME-669 - Test Series C1, An Experimental Determination of the Pressure Loss Coefficients for the Inner Reflector-Outer Reflector Annulus, V. R. Amatange lo, 1/29/64. 3. WANL-TME-826 - An Experimental Determination of the Loss Coefficients for the Inner Impedance Ring Using Air and Hydrogen, O. P. Gormley.

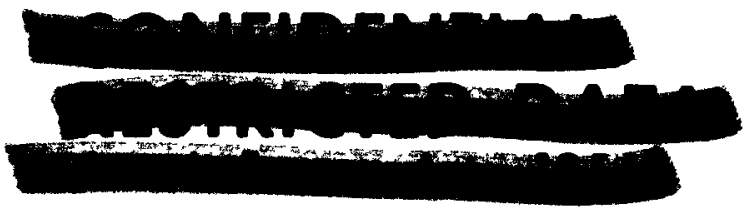




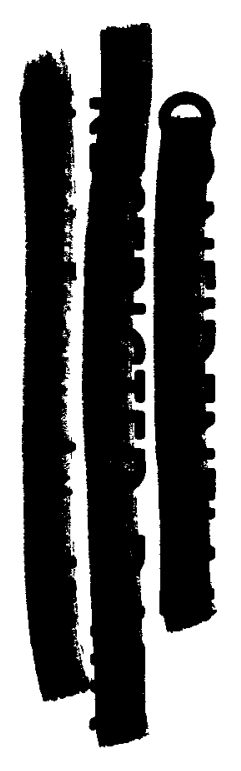

or
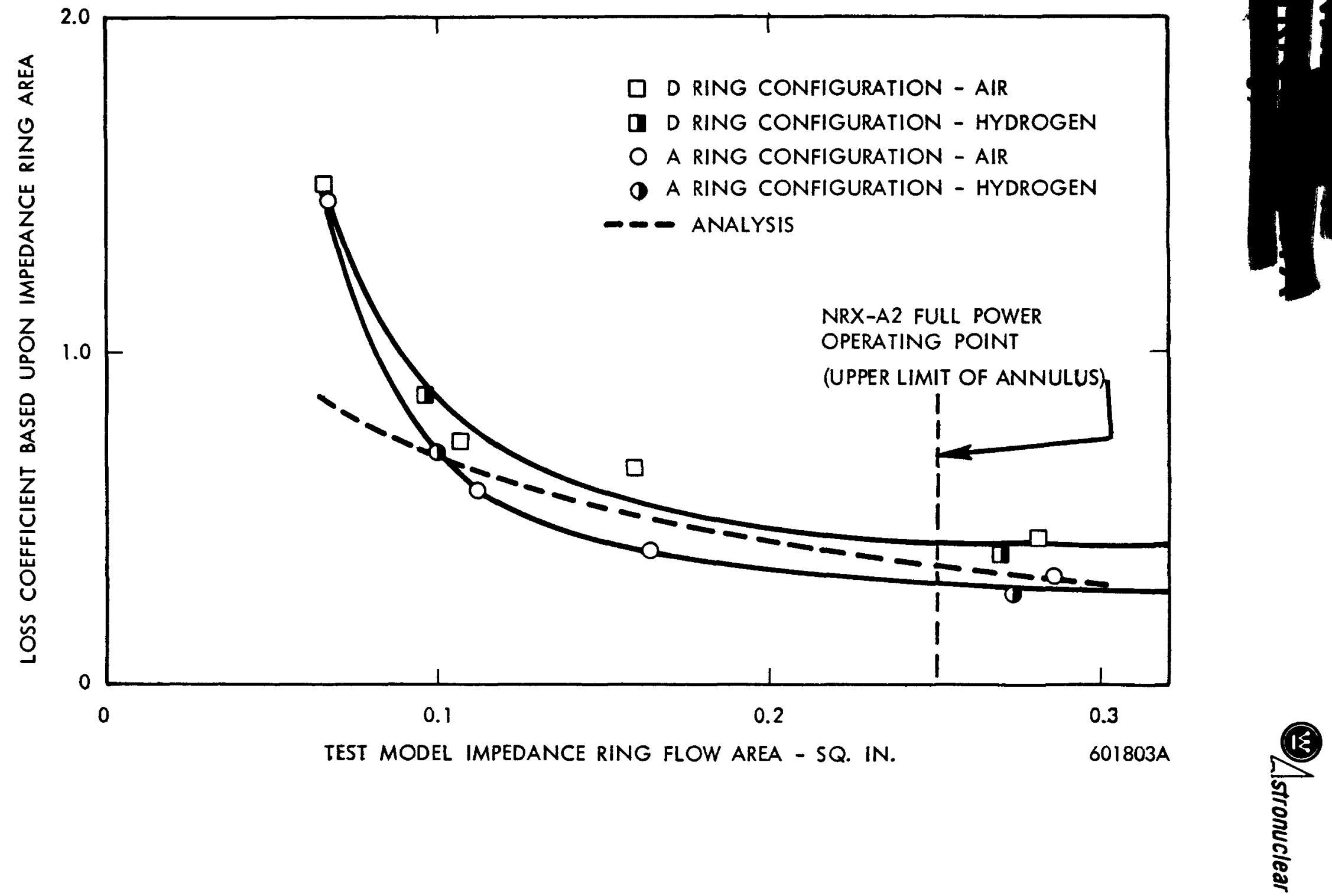

FIGURE 3 LOSS COEFFICIENTS AS A FUNCTION OF MODEL IMPEDANCE RING FLOW AREA 


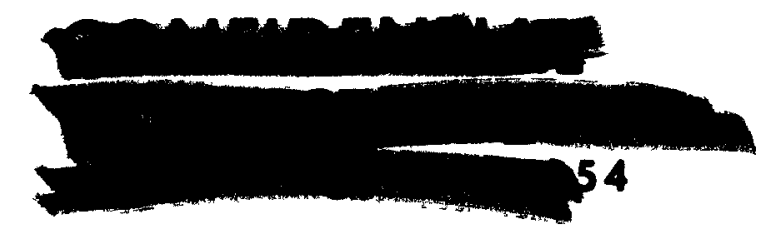

The dashed curve in figure 3 shows the analytically predicted value of the loss coefficient. This prediction is based upon the assumption that the flow sees the impedance ring as a sudden contraction followed by a sudden expansion. As can be seen, the analytical prediction falls between the experimental values for the two configurations, except for the very small annuli (less than .075 inches). Therefore, it appears that the analysis predicts the performance of this impedance ring in a satisfactory manner in the range of annular gaps expected within the reactor.

\section{Outer Reflector-Pressure Vessel Annulus Impedance Ring}

The impedance ring in the annulus between the outer reflector and the pressure vessel wall consists of 360 holes, 0.113 inches in diameter, located in the dome end support ring flange, at the annulus exit. The flow through the impedance ring discharges through clearance slots in the shield flange to the plenum at the exit of the first pass of the shield.

Since the support ring is trapped in the pressure vessel flange, no significant dimensional changes are expected to occur in the annulus near the entrance to the impedance ring. Thus, both the impedance area and void fraction (i.e. ratio of impedance ring area to channel area) remain relatively constant during all phases of reactor operation.

A model consisting of a $6^{\circ}$ sector ( 6 impedance holes) of the impedance ring and a corresponding sector of the outer reflector-pressure vessel annulus, shield flange, and first pass shield exit plenum was flow tested with air to check the analytical estimates of this loss coefficient.

Test results ${ }^{4}$ indicate that the loss coefficient (based upon the impedance ring area) was constant at a value of 1.22 over a Reynolds Number range of $4.5 \times 10^{4}$ to $1.8 \times 10^{5}$ prior to the onset of significant compressibility effects. This experimental value can be compared to the analytically predicted value by converting it to a loss coefficient based upon the annulus dimension shown in Table 1.

4. WANL-TME-825 - An Experimental Determination of the Outer Impedance Ring Loss Coefficient, W. L. Jacob.

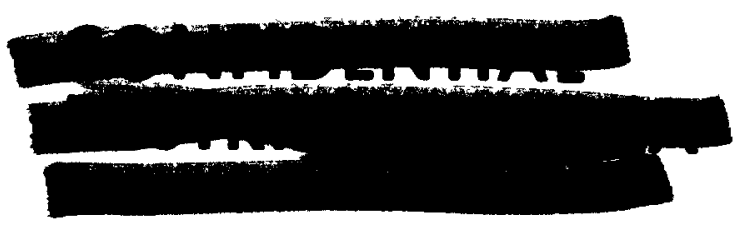




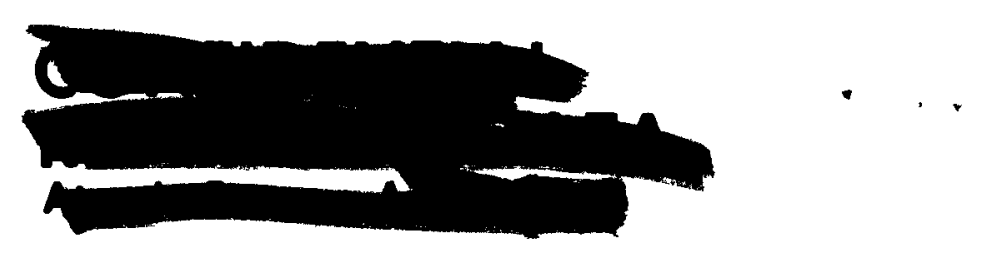

The slight discrepancy between the two values is undoubtedly due to the less severe contraction and expansion actually occurring with the reactor hardware in comparison to the sudden contraction and sudden expansion assumed in the analysis. The resulting change in the loss coefficient for this channel, to be used in the reflector flow balance, is only 18 percent and will not result in a significant change in flow distribution, material temperatures, or bulk coolant temperatures. Previous analysis ${ }^{7}$ has shown that a 30 percent decrease in this loss coefficient will result in bulk fluid temperature and wall temperature changes in the other reflector cooling channels of less than 3 percent (e.g., the maximum temperature on the control vane would increase from $561^{\circ} \mathrm{R}$ to $576^{\circ} \mathrm{R}$ and the bulk coolant temperature at the exit of this portion of the control vane would increase from $384^{\circ} R$ to $\left.393^{\circ} \mathrm{R}\right)$.

\section{TABLE 1}

Loss Coefficient Based Upon Impedance Area

Experiment

Reynolds Number at Impedance Ring
Loss Coefficient Based Upon Annulus Area

116

95

Loss Coefficient*for Use in MCAP Flow Balance 100

* This loss coefficient is based upon the annulus area but has been corrected for the first pass shield pressure drop. This correction is necessary since the reflector flow balance is made between the inlet and exit pressures and the outer reflector-pressure vessel annulus exhausts to the exit plenum of the first pass of the shield.

7. WANL-TNR-128, Volume III, Reactor Analysis of NRX-A, Thermal and Fluid Flow Analysis, September, 1963, Chapter 6.

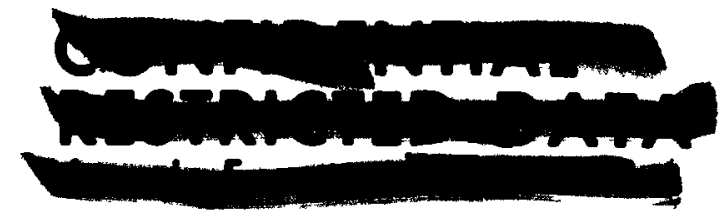

